NASA/TM—2007-214984

\title{
Robust Low-Cost Cathode for Commercial Applications
}

Michael J. Patterson

Glenn Research Center, Cleveland, Ohio 


\section{NASA STI Program . . . in Profile}

Since its founding, NASA has been dedicated to the advancement of aeronautics and space science. The NASA Scientific and Technical Information (STI) program plays a key part in helping NASA maintain this important role.

The NASA STI Program operates under the auspices of the Agency Chief Information Officer. It collects, organizes, provides for archiving, and disseminates NASA's STI. The NASA STI program provides access to the NASA Aeronautics and Space Database and its public interface, the NASA Technical Reports Server, thus providing one of the largest collections of aeronautical and space science STI in the world. Results are published in both non-NASA channels and by NASA in the NASA STI Report Series, which includes the following report types:

- TECHNICAL PUBLICATION. Reports of completed research or a major significant phase of research that present the results of NASA programs and include extensive data or theoretical analysis. Includes compilations of significant scientific and technical data and information deemed to be of continuing reference value. NASA counterpart of peer-reviewed formal professional papers but has less stringent limitations on manuscript length and extent of graphic presentations.

- TECHNICAL MEMORANDUM. Scientific and technical findings that are preliminary or of specialized interest, e.g., quick release reports, working papers, and bibliographies that contain minimal annotation. Does not contain extensive analysis.

- CONTRACTOR REPORT. Scientific and technical findings by NASA-sponsored contractors and grantees.
- CONFERENCE PUBLICATION. Collected papers from scientific and technical conferences, symposia, seminars, or other meetings sponsored or cosponsored by NASA.

- SPECIAL PUBLICATION. Scientific, technical, or historical information from NASA programs, projects, and missions, often concerned with subjects having substantial public interest.

- TECHNICAL TRANSLATION. Englishlanguage translations of foreign scientific and technical material pertinent to NASA's mission.

Specialized services also include creating custom thesauri, building customized databases, organizing and publishing research results.

For more information about the NASA STI program, see the following:

- Access the NASA STI program home page at http://www.sti.nasa.gov

- E-mail your question via the Internet to help@sti.nasa.gov

- Fax your question to the NASA STI Help Desk at 301-621-0134

- Telephone the NASA STI Help Desk at 301-621-0390

- Write to: NASA Center for AeroSpace Information (CASI) 7115 Standard Drive Hanover, MD 21076-1320 
NASA/TM-2007-214984

\section{Robust Low-Cost Cathode for Commercial Applications}

Michael J. Patterson

Glenn Research Center, Cleveland, Ohio

Prepared for the

43rd Joint Propulsion Conference

sponsored by the American Institute of Aeronautics and Astronautics

Cincinnati, Ohio, July 8-11, 2007

National Aeronautics and

Space Administration

Glenn Research Center

Cleveland, Ohio 44135 


\section{Acknowledgments}

The author gratefully acknowledges funding provided through the Commercial Technology Office at NASA Glenn Research Center.

Trade names and trademarks are used in this report for identification only. Their usage does not constitute an official endorsement, either expressed or implied, by the National Aeronautics and Space Administration.

Level of Review: This material has been technically reviewed by technical management.

Available from

NASA Center for Aerospace Information 7115 Standard Drive

Hanover, MD 21076-1320
National Technical Information Service 5285 Port Royal Road Springfield, VA 22161 


\title{
Robust Low-Cost Cathode for Commercial Applications
}

\author{
Michael J. Patterson \\ National Aeronautics and Space Administration \\ Glenn Research Center \\ Cleveland, Ohio 44135
}

\begin{abstract}
Under funding from the NASA Commercial Technology Office, a cathode assembly was designed, developed, fabricated, and tested for use in plasma sources for ground-based materials processing applications. The cathode development activity relied on the large prior NASA investment and successful development of high-current, high-efficiency, long-life hollow cathodes for use on the International Space Station Plasma Contactor System. The hollow cathode was designed and fabricated based on known engineering criteria and manufacturing processes for compatibility with the requirements of the plasma source. The transfer of NASA GRC-developed hollow cathode technology for use as an electron emitter in the commercial plasma source is anticipated to yield a significant increase in process control, while eliminating the present issues of electron emitter lifetime and contamination.
\end{abstract}

\section{Nomenclature}

COTS Commercial Off-the-Shelf

ISS International Space Station

MOA Market Opportunity Analysis

PECVD Plasma enhanced chemical vapor deposition

sccm Standard cubic centimeters per minute

UHP Ultra-high purity

\section{Introduction}

A number of inert gas hollow cathodes have been developed at NASA Glenn Research Center (GRC) for a variety of electric propulsion applications, for emission current requirements ranging from $100 \mathrm{~mA}$ to $100 \mathrm{~A}$ (ref. 1). Associated development activities include improving cathode efficiency, understanding life-limiting mechanisms and extending life, developing compact cathode assemblies for low-power electric propulsion, and developing high-current cathode designs for high-power electric engines. Cathode assemblies have also been developed for spacecraft charge control for the International Space Station (ISS), for low-electron temperature space plasma simulation, and for ground-based materials processing applications.

A Market Opportunity Analysis (MOA) of NASA's cathode technology was executed for NASA's commercial technology office by the Great Lakes Industrial Technology Center. The MOA concluded that NASA's cathode technology dominates the space applications market and has value in the growing terrestrial applications market. It also concluded that existing commercial suppliers of hollow cathodes would benefit from incorporating NASA's technology. Based on the MOA, NASA began actively pursuing commercialization of cathode technology via licensing agreements with U.S. private industry for both space and terrestrial applications. The licensing agreements include rights to patented technology, and transfer of know-how and trade secrets. NASA patents cover design aspects, manufacturing processes, and operating procedures for the cathodes. Part of each license agreement describes a plan for NASA to train the licensee and transfer this additional information.

One such activity NASA entered involved a joint effort with a U.S. firm for the development of a hollow cathode for use as an electron source for the production of diamond-like coatings, as replacement for thermionic filament cathodes. This activity is described in this publication. 


\section{Cathode Assembly Design}

This section describes the intended application, the associated constraints and requirements, and the cathode assembly design solution.

\section{A. Application}

A commercial firm has developed a process for generation of diamond-like thin film coatings. These coatings can contain $\mathrm{C}, \mathrm{H}, \mathrm{Si}$, and $\mathrm{O}$, are hard, low friction, wear resistant, have low surface energy, and through the addition of metals, can be grown with a broad range of electrical resistivities. The coatings are being commercialized for electrosurgical blades and for printer heads and other commercial applications are being developed. The diamond-like thin films are deposited via plasma-enhanced chemical vapor deposition (PECVD). The plasma is sustained using a biased hot tungsten filament for electron generation (the cathode), with the vacuum facility surfaces as the source anode.

The hot filament cathode introduces several problems including carbonization and embrittlement (resulting in limited cathode lifetime), low plasma density, low deposition rates, low throughput, poor process control, and poor reproducibility. For several commercial applications, particularly those in the semiconductor industry, the presence of the tungsten cathode filament makes the process incompatible with existing semiconductor deposition processes and equipment. For these reasons, the firm was interested in exploring alternative electron sources which are compatible with their manufacturing processes. Discussions were held with NASA to examine the possibility of using a hollow cathode as an electron source to replace the tungsten filament.

Based on these initial discussions, the firm anticipated that the hollow cathode would significantly improve the deposition process, making it more commercially viable. Specifically, increased process control, high plasma density, high throughput, and improved reproducibility were expected, while concerns associated with the filament lifetime and contamination would be eliminated. As a consequence a joint effort was undertaken to design and construct a cathode that would meet the requirements of the PECVD process in terms of output and plasma properties.

Once the cathode was built and tested at NASA, it would be installed into one of the existing deposition chambers, replacing the tungsten filament assembly. Using a statistically designed series of experiments, the firm would determine the optimum operating parameters of the cathode. Output of the cathode as well as other process controls would be the operating variables. The properties of the resulting coatings would be measured in order to determine the optimum operating conditions. Feedback from this data would, through the designed experiments, be used to further optimize the process. Once the operation of the cathode was optimized, the firm would work with NASA to determine what, if any, further modifications of the cathode would be necessary for use in the PECVD process.

\section{B. Constraints and Requirements}

The ground-based materials processing application of the cathode technology poses interesting, different challenges as compared to the typical NASA space application. These differencesconstraints—are listed in table 1 , and they play a major role in the design approach.

TABLE 1.-CATHODE ASSEMBLY CONSTRAINTS

\begin{tabular}{|l|l|}
\hline \multicolumn{1}{|c|}{ NASA application } & \multicolumn{1}{c|}{ Commercial application } \\
\hline$\checkmark$ Extreme reliability required; $>99$ percent & Modest reliability \\
$\checkmark$ Function mission critical & \\
\hline$\checkmark$ Extremely long-life; >10 000 hr & $\checkmark$ Process run 2 to 4 hr \\
$\checkmark$ High number of ignitions; $>1000$ & $\checkmark$ 2 Process cycles \\
\hline Manufacturing cost relatively unimportant & Cost extremely important \\
\hline Interfaces and environment adjusted to accommodate hollow cathode & Cathode must accommodate environment \\
\hline
\end{tabular}


For the typical NASA application of cathode technology (ISS, Deep Space 1, etc.), functionality and reliability are paramount. As an example, the hollow cathode in the plasma contactor unit on ISS is considered mission critical, requiring two-fault tolerance. Requirements for this cathode include a minimum life time of $18000 \mathrm{hr}$ with an ignition reliability of $>99$ percent for 6000 ignitions. These and other highly demanding operational requirements along with the mission critical nature of its operation increase manufacturing costs. Despite this fact, cost of manufacturing is relatively unimportant as compared to functionality and reliability, and as such little emphasis is applied in this area." Additionally, much emphasis is applied to ensuring that the interfaces and environments in which the cathode are subjected to be adjusted to accommodate the cathode. Examples include stringent propellant purity requirements which may require costly and complex feed system preparations, and highly restrictive environmental exposure limits for the cathode which necessitate implementing burdensome cover-gas purges during ground processing and launch operations.

The PECVD application is essentially on the opposite end of the spectrum in constraints as compared to the NASA space applications. Processing cost is paramount, a portion of which is the cathode cost. Typical deposition runs are of the order of 2 to $4 \mathrm{hr}$ in duration, with the tungsten cathode filament lasting at most 2 runs prior to failure, and costing about $\$ 8$ each—resulting in a cathode cost of about $\$ 1$ to $\$ 2$ per hour of operation. A replacement cathode would need to achieve this cost target, unless significant process improvements are achieved otherwise. Since process runs are short in duration and the facility is cycled to atmosphere frequently an occasional cathode failure is tolerable. Finally, the cathode cannot impose burdensome interfaces or environmental constraints which could negatively impact the PECVD process.

Working within the imposed constraints (table 1), NASA and the commercial firm jointly developed requirements and specifications (goals) for a cathode assembly for the PECVD process. These are listed in table 2. The requirements include operational, design, and cost requirements.

TABLE 2.-CATHODE ASSEMBLY REQUIREMENTS, SPECIFICATIONS, AND DESIGN SOLUTION

\begin{tabular}{|c|c|c|c|}
\hline Type & Requirement & Specification & Design solution/Approach \\
\hline \multirow[t]{9}{*}{ Operational } & Electron emission current & 1.0 (nominal) $-3.0 \mathrm{~A}$ & $1.0-3.0 \mathrm{~A}$ \\
\hline & Working gas & Ar inert gas; UHP grade & Ar; UHP grade \\
\hline & Gas flow rate & $<20 \mathrm{sccm}$ & $<20 \mathrm{sccm} ; 10 \mathrm{sccm}$ nominal \\
\hline & Required life & $100 \mathrm{hr}$ minimum; >1 $000 \mathrm{hr}$ goal & $>1000 \mathrm{hr}$ (estimate) \\
\hline & Input power & $<100 \mathrm{~W}$ & $<50 \mathrm{~W}$ (typical) \\
\hline & Ignition time & $<6 \min$ & $<6 \min$ \\
\hline & Number of cathode ignitions & 50 minimum; goal $>500$ & $>500$ (estimate) \\
\hline & $\begin{array}{ll}\checkmark & \text { Rapid turn-around required } \\
\checkmark & \text { Rapid start-up from turn-around }\end{array}$ & $\begin{array}{ll}\checkmark & \text { Quick vacuum-atmosphere- } \\
& \text { vacuum cycling } \\
\checkmark & \text { Maximum } 15 \text { min } \\
\end{array}$ & $\begin{array}{ll}\checkmark & 1 \text { hr post-operation cool down } \\
\checkmark & <15 \text { min start-up }\end{array}$ \\
\hline & Single set-point operation & $1.0 \mathrm{~A},<20 \mathrm{sccm}$ nominal & Compliant \\
\hline \multirow[t]{5}{*}{ Design } & Mechanical & $\begin{array}{l}\text { Compatibility with existing vacuum } \\
\text { facility and plasma source }\end{array}$ & $\begin{array}{ll}\checkmark & \text { Hollow cathode mounted from a } \\
& 2-3 / 4 \text { in. diameter Conflat }{ }^{\dagger} \text { flange } \\
\checkmark & 1 / 4 \text { in. Swagelok }{ }^{\ddagger} \text { gas connector }\end{array}$ \\
\hline & \multirow[t]{2}{*}{ Electrical } & $\begin{array}{l}\text { Compatibility with existing vacuum } \\
\text { facility and plasma source }\end{array}$ & $\begin{array}{l}\text { Hollow cathode electrically isolated } \\
\text { from flange assembly }\end{array}$ \\
\hline & & $\begin{array}{l}\text { Use of } \mathrm{COTS}^{\S} \text { power supplies for } \\
\text { operation }\end{array}$ & Compliant \\
\hline & Compatible with plasma source & Thin film deposition & All insulators shadow-shielded \\
\hline & Serviceable & Repair in field & Minimize parts, simple design \\
\hline Cost & $\begin{array}{l}\text { Cost competitive to alternative } \\
\text { cathode }\end{array}$ & $\begin{array}{l}\text { Achieve cost target of } \$ 1 \text { to } \$ 2 \text { per } \\
\text { hour of operation; } \$ 100 \text { to } \$ 200 \text { per } \\
\text { cathode for } 100 \text { hr of operational } \\
\text { lifetime (minimum) }\end{array}$ & $\begin{array}{l}\text { Maximize use of commercially- } \\
\text { available subassemblies to reduce } \\
\text { manufacturing costs }\end{array}$ \\
\hline
\end{tabular}

\footnotetext{
*Typical costs for proto-flight and flight cathodes manufactured by NASA are of the order of \$50 to \$100 K per unit, a number consistent with quotations provided to the author recently by 2 U.S. aerospace companies.

${ }^{\dagger}$ Conflat is a registered trademark of Varian Associates.

${ }^{\ddagger}$ Swagelok is a trademark of Swagelok Fluid System Technologies Inc.

${ }^{\S}$ COTS; commercial-off-the-shelf.
} 
The operational requirements include current, gas type and flow rate, life, and input power, among other. The required electron emission current-current from the cathode to the vacuum facility surfaces which act as the source anode-is 1 to $3 \mathrm{~A}$, with $1.0 \mathrm{~A}$ typical. The working gas for the hollow cathode would be UHP grade Ar at flow rates less than $20 \mathrm{sccm}$. The required life time would be $>100 \mathrm{hr}$, with $>1000 \mathrm{hr}$ as a goal. Input power levels would need to be less than $100 \mathrm{~W}$, with ignition times $<6$ min. Total number of required ignitions would be 50 (minimum) with a goal of $>500$. The cathode would have to accommodate rapid turn-around of the processing facility from vacuum-to-atmosphere and back to vacuum again, with the ability to rapidly restart the cathode ( $<15 \mathrm{~min})$ once the facility achieves high vacuum $\left(10^{-3} \mathrm{~Pa}\right)$.

The mechanical and electrical design of the cathode would have to be compatible with the existing vacuum facilities and plasma source. This would dictate that 2-3/4 in. diameter Conflat flanges be used for integration into the facility, and that the UHP Ar gas connection uses a 1/4 in. Swagelok fitting. The hollow cathode would also have to be electrically isolated from the flange and anode-potential vacuum facility. It was also desired that the cathode function with commercially available off-the-shelf (COTS) power supplies, be resilient to deposition of conductive films, and be readily serviceable. The cathode would also need to be cost-competitive to the tungsten filament; on the order of \$1 to \$2 per hour of operation.

\section{Design Solution}

The cathode assembly developed for the PECVD process is built from two major sub-assemblies; the flange assembly, and the hollow cathode. The flange assembly provides all of the mechanical, electrical, and gas interfaces to the vacuum facility and plasma source for operation of the hollow cathode. The second assembly is the hollow cathode which is the limited-life active electron emission source.

\section{Flange Assembly}

To simplify integration it was desired to integrate all cathode interfaces onto a single 2-3/4 in. Conflat flange. A special gas and power vacuum flange (fig. 1) was designed which satisfies all the operational requirements of the hollow cathode. Features of the flange assembly include:

$\checkmark$ Mechanically supports the hollow cathode;

$\checkmark \quad$ Provides all of the electrical power interfaces (1 each for the hollow cathode keeper, heater, and cathode common return) to operate the hollow cathode;

$\checkmark$ Provides the single gas feed line with $1 / 4$ in. diameter Swagelok fittings to operate the hollow cathode;

$\checkmark \quad$ Provides electrical isolation of the hollow cathode from the flange assembly and vacuum facility via use of a shadow-shielded cryogenic break which inhibits Paschen breakdown;

$\checkmark$ Provides integral ceramic electrical stand-offs all of which are shadow-shielded to inhibit deposition of conductive thin films.

The hollow cathode mounts directly onto the $1 / 4$ in. Swagelok fitting shown on the right-hand side of the illustration in figure 1, the vacuum-side of the 2-3/4 in. Conflat flange. 


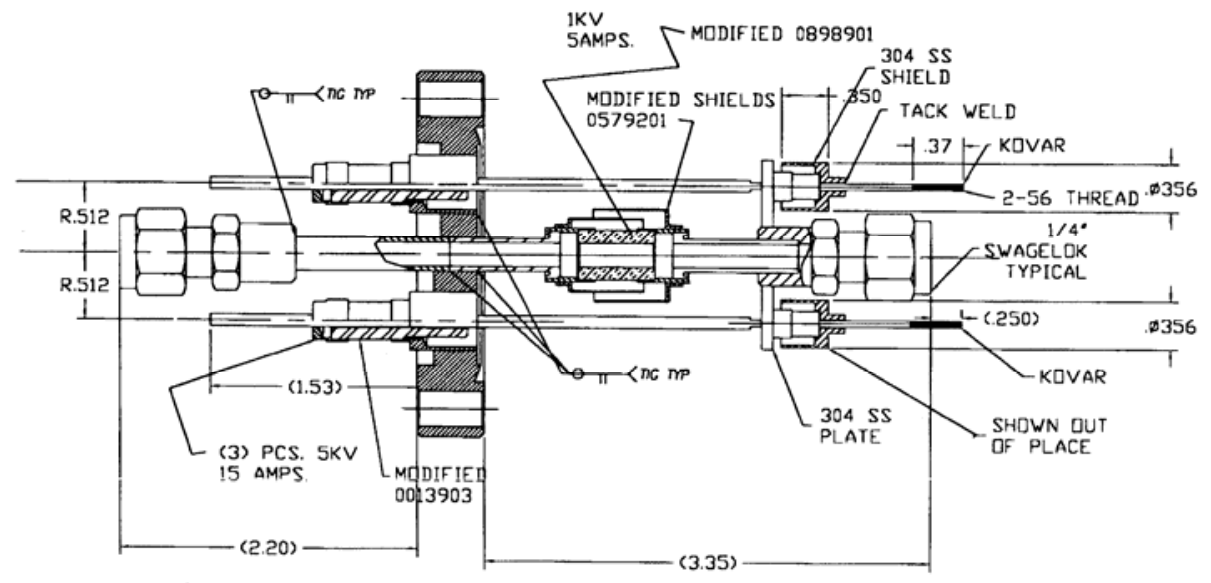

Figure 1.-Flange assembly: Special gas and power feedthrough with shielded cryogenic break.

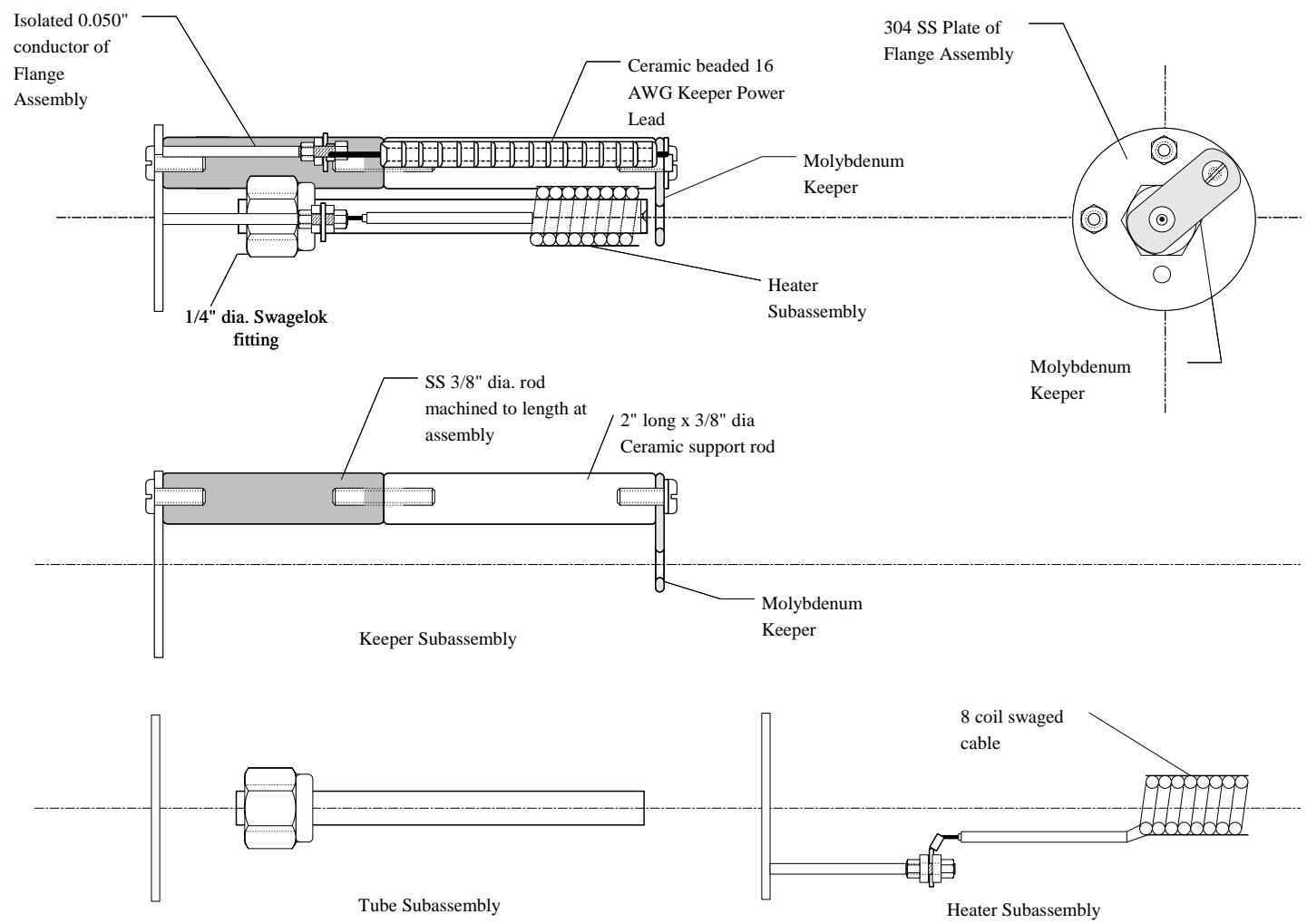

Figure 2.-Hollow cathode: Top view fully-assembled; lower views major subassemblies.

\section{Hollow Cathode}

The second major sub-assembly of the cathode assembly is the hollow cathode. The hollow cathode is the active electron emitter which substitutes directly for the tungsten filament cathode. It is the limitedlife component. The hollow cathode consists of 3 sub-assemblies (reference fig. 2 and table 3), including the keeper subassembly, the tube subassembly, and the heater subassembly. 
TABLE 3.-CATHODE ASSEMBLY PARTS LIST AND DESCRIPTION

\begin{tabular}{|c|c|}
\hline Cathode assembly parts list & Description \\
\hline Flange assembly & NASA design; may be purchased from Insulator Seal, Inc. \\
\hline \multicolumn{2}{|l|}{ Hollow cathode } \\
\hline \multicolumn{2}{|l|}{ Keeper subassembly } \\
\hline Keeper electrode & Molybdenum \\
\hline Ceramic support rod & $\begin{array}{l}\text { 3/8 in. diameter, } 2 \text { in. long Grade L-5 Steatite per Military No. NL- } \\
\text { 523W01-06 }\end{array}$ \\
\hline Metal spacer & 3/8 in. diameter stainless steel rod machined at assembly \\
\hline Power lead & 16 AWG per Mil Spec MIL-W-81381 \\
\hline Power connect & Solderless non-insulating 14 to 16 AWG steel connector \\
\hline \multicolumn{2}{|l|}{ Tube subassembly } \\
\hline Tube $^{* *}$ & $\begin{array}{l}3 \text { in. long Molybdenum alloy } 1 / 4 \text { in. diameter, } 0.020 \text { in. nominal wall } \\
\text { thickness }\end{array}$ \\
\hline Orifice plate & Tungsten alloy, $0.008 \pm 0.0005$ in. diameter orifice \\
\hline Emitter $^{\dagger+}$ & 1/4 in. diameter commercial-grade \\
\hline Emitter retainer $^{\# \#}$ & Machined Tantalum plug \\
\hline Gas connector & $1 / 4$ in. diameter stainless steel Swagelok ${ }^{\S \S}$ fitting \\
\hline \multicolumn{2}{|l|}{ Heater subassembly } \\
\hline Swaged cable & Fabricated from 0.096 in. diameter bulk heater cable; Ta-MgO-Ta \\
\hline Radiation shield & Fabricated from 0.0005 in. thick Tantalum foil \\
\hline Power connect & Solderless non-insulating 14-16 AWG steel connector \\
\hline
\end{tabular}

The hollow cathode works on the principle of field-enhanced thermionic emission. Direct current is applied to the heater subassembly which consists of a helical coiled swaged cable surrounding the tube assembly, raising the emitter inside the tube to thermionic temperature. With the presence of an inert gas passing through the tube and a high-voltage applied to the keeper (a small anode located directly downstream of the tube) an electrical discharge is initiated via emission of electron current from the emitter to the keeper. Ion bombardment of the emitter from the plasma being generated within the tube subassembly sustains the emitter temperature allowing cut-off of power to the heater. The circulating electron current between the tube subassembly and the keeper subassembly sustains the electron emission. A bias voltage applied between the tube subassembly and an external surface acting as an anode (such as the vacuum facility walls) allows for additional electron emission current to flow at which point the circulating current between the cathode and keeper can be cut-off.

Based on the desired emission current range of 1 to $3 \mathrm{~A}$, a hollow cathode constructed of a 1/4 in. diameter tube subassembly was selected. The orifice diameter of the plate attached to the end of the tube was sized to yield hollow cathode temperatures which accommodate both stable operation and long life; a range of about 825 to $1150{ }^{\circ} \mathrm{C}$. Electron emission arises from a commercial-grade emitter constructed from porous tungsten cylinder impregnated with barium oxide, calcium oxide, and aluminum oxide.

The cathode assembly was constructed using an open-geometry ${ }^{* * *}$ keeper subassembly. A keeper refers to a secondary anode that is used to maintain the operation of the cathode when there is no primary discharge to the main anode. The keeper can improve operation of the cathode (facilitate ignition, reduce flow rate, increase dynamic current range and plasma source throttling, provide for an independent control of discharge voltage). However it also (if the keeper discharge is maintained after the primary discharge is struck) requires more total power supplies for operation, and consumes more power. For the PECVD process a keeper may in eventuality not be required, thereby eliminating this entire subassembly. The geometry and position of the keeper were established based on known design criteria.

\footnotetext{
${ }^{* * *}$ An alternative, lower-cost tube material is Tantalum.

${ }^{+\dagger}$ An alternative, low-cost emitter may be manufactured from textured Tantalum foil doped with R-500, a barium carbonate and strontium carbonate mixture. No emitter retainer is required.

\#This component can be eliminated by welding of the emitter electrical leads directly to the tube wall.

${ }^{\S}$ Swagelok is a trademark of Swagelok Fluid System Technologies Inc.

**** Open-geometry refers to the fact that the interelectrode gap between the tube subassembly and the keeper subassembly is radially open. An alternative design normally used in space cathodes is an enclosed-geometry keeper which consists of a cylinder and orifice plate which is placed over the tube and heater subassemblies and encapsulates them. The advantages of the enclosed design are gas efficiency. However this design is more complex to manufacture and assemble and is not warranted for the PECVD application.
} 
The heater subassembly was constructed of commercially-available bulk heater cable. The author has used this approach for laboratory cathodes on many occasions, and although no specific cyclic life tests of this heater design have been performed, no heater failures have been experienced. The cable was wound to the appropriate diameter and one end was tungsten inert gas welded to provide the power return through the sheath. This approach is significantly different than that used for space cathodes, where the swaged cable is manufactured by NASA from the individual constituents and undergoes a complex series tests and inspections throughout the manufacturing process to ensure product control. Since the final swaged center conductor diameter for the heater fabricated from the commercial bulk heater cable is slightly larger than that of the NASA space cathode heaters, some minor differences (increase) in input power are required for emitter conditioning and ignition.

The cathode assembly, consisting of both the flange assembly and the hollow cathode, is shown in figures 3 and 4 as an integrated unit. Operation of the cathode assembly requires use of a (commercial)

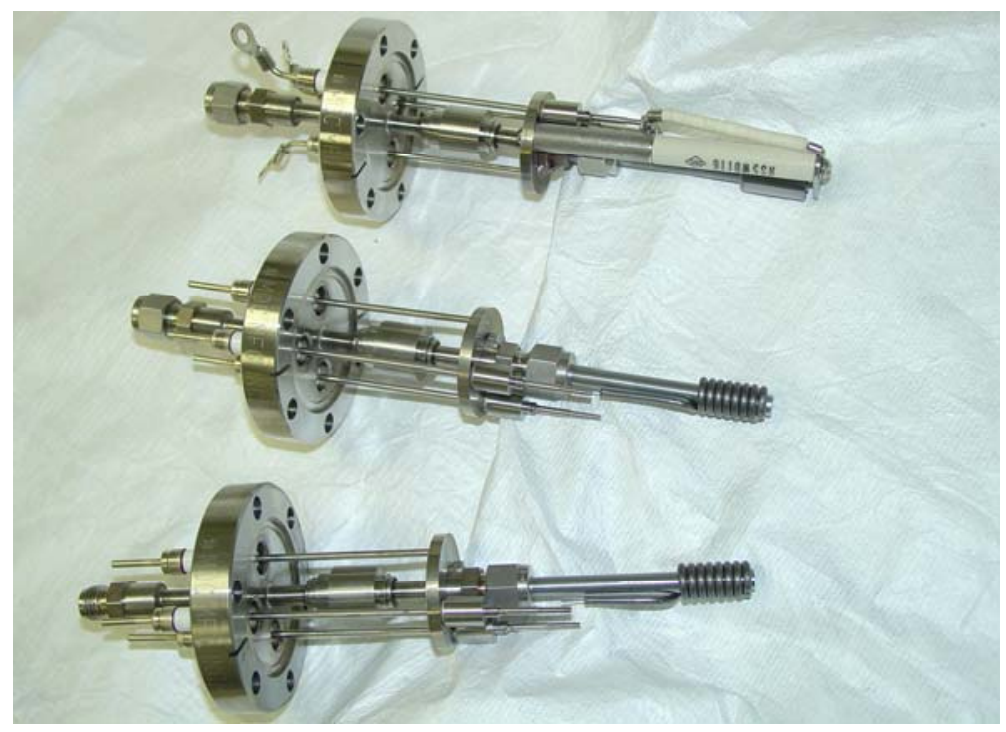

Figure 3.-Cathode Assemblies; top assembly completed, lower two assemblies in partial state of assembly.

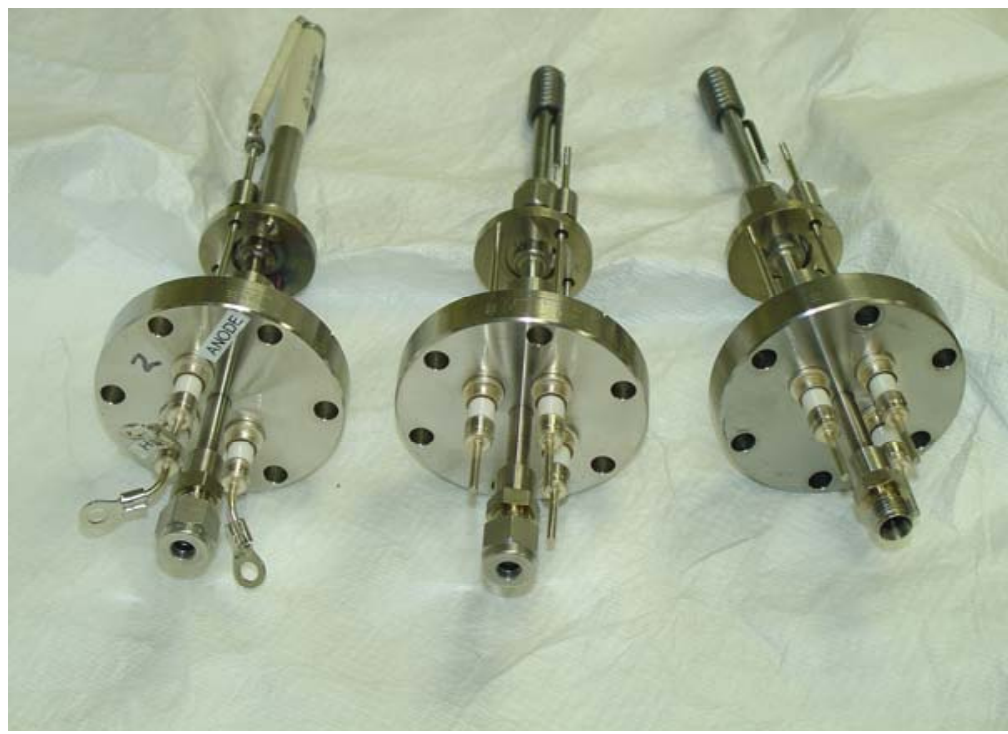

Figure 4.-Cathode Assemblies; viewed from atmospheric side of flange assembly. 


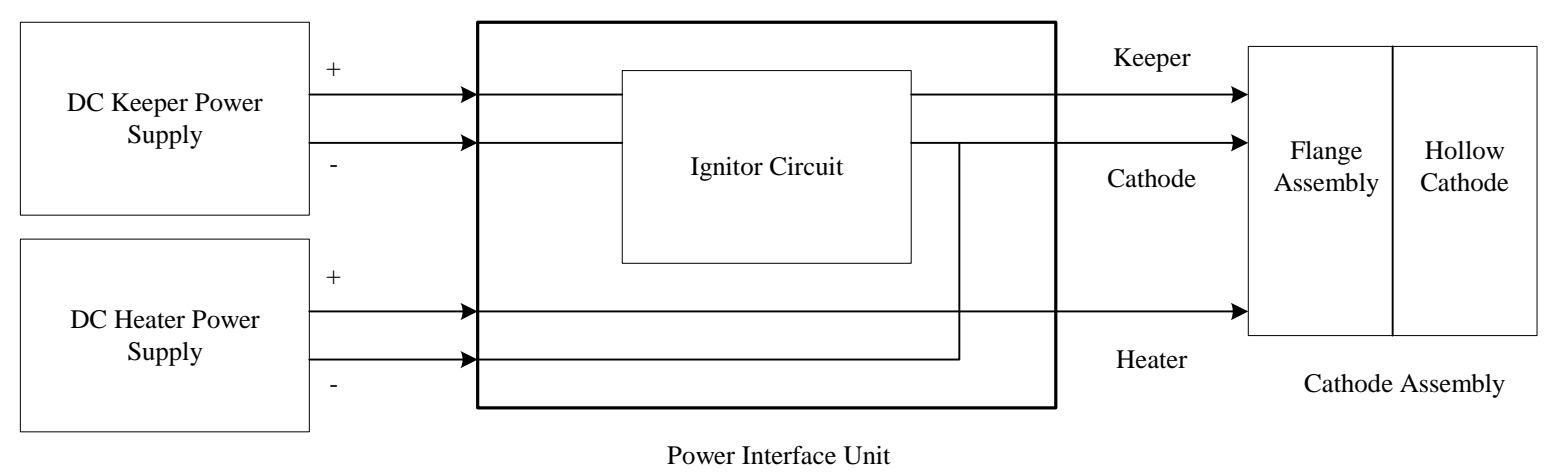

Figure 5.-Electrical configuration for operation of the cathode assembly.

DC power supply to energize the heater subassembly, and a (commercial) DC power supply to sustain the cathode-to-keeper discharge. The heater and keeper power supplies are $16 \mathrm{~V}-10 \mathrm{~A}$ and $55 \mathrm{~V}-3$ A sources respectively. An additional DC power supply would be used to bias the cathode assembly with respect the vacuum facility walls to emit electron current from the hollow cathode for the PECVD discharge process. Alternately this function could be performed by the keeper power supply if the keeper was not used. To ensure cathode ignition an inductively-coupled circuit provides a high-voltage ignition pulse between the tube subassembly and the keeper subassembly. This circuit is contained within a power interface unit which connects the keeper and heater power supplies to the cathode assembly at the interface terminals on the atmospheric-side of the flange assembly. This arrangement is shown in figure 5.

\section{Performance}

Performance characterization tests of the cathode assembly were conducted to evaluate its operation against the requirements. A small cryogenically-pumped vacuum facility at NASA GRC was used to conduct the testing (ref. 2). The facility approximated the dimensions and pumping characteristics of the commercial firms PECVD chamber ${ }^{\text {t†t }}$ and was equipped to operate hollow cathodes. The tests included establishing heater input current requirements for emitter conditioning and hollow cathode ignition, and assessing the emission characteristics of the hollow cathode including operating temperatures over the required operating range.

Ignition characteristics of the cathode assembly were reliable and repeatable and consistent with space cathodes developed by the author, with ignition times less than 6 min from application of heater power. This was achieved by ignition directly to the keeper, and also ignition directly to the vacuum facility walls which are at anode potential. Hollow cathode orifice plate and gas connector temperatures were obtained over the range of emission currents using Pt-Rh thermocouples. Figure 6 shows the cathode assembly mounted inside of the vacuum facility, with a ceramic-beaded Pt-Rh thermocouple attached to the orifice plate.

The cathode assembly was operated over a range of emission currents (separately to both the keeper and to the vacuum facility walls), and Ar flow rates. At each condition the cathode assembly was allowed to stabilize at which point DC and AC currents and voltages were recorded along with cathode temperatures. Cathode assembly temperatures were also obtained during shutdown to determine how rapidly the assembly would cool.

The cathode assembly was characterized from 0.75 A to 3.0 A electron emission. Below 0.75 A the hollow cathode would not operate stably, and above 3.0 A exceeded the maximum requirement. The cathode assembly required a minimum Ar flow rate of $8 \mathrm{sccm}$ Ar to operate stably; data were obtained

\footnotetext{
${ }^{+\dagger}$ Facility dimensions are about $1.2 \mathrm{~m}^{2}$, with approximately 2000 liter-per-second pumping speed, and base pressure of $<2 \times 10^{-3} \mathrm{~Pa}$.
} 


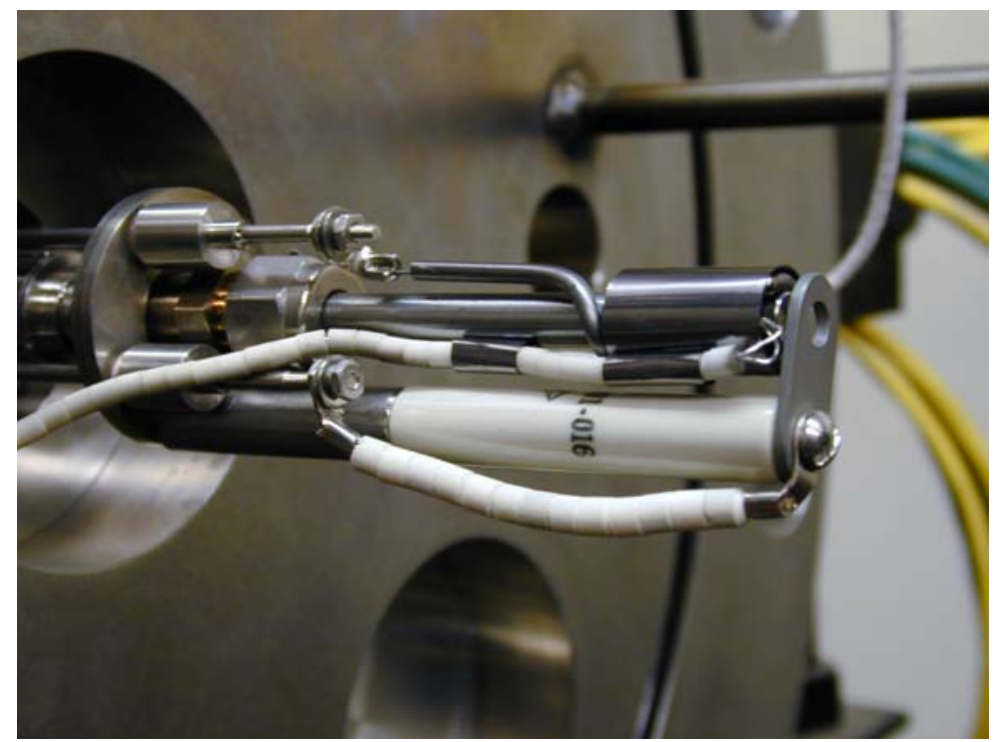

Figure 6.-Cathode assembly mounted in vacuum facility; Pt-Rh thermocouple attached.

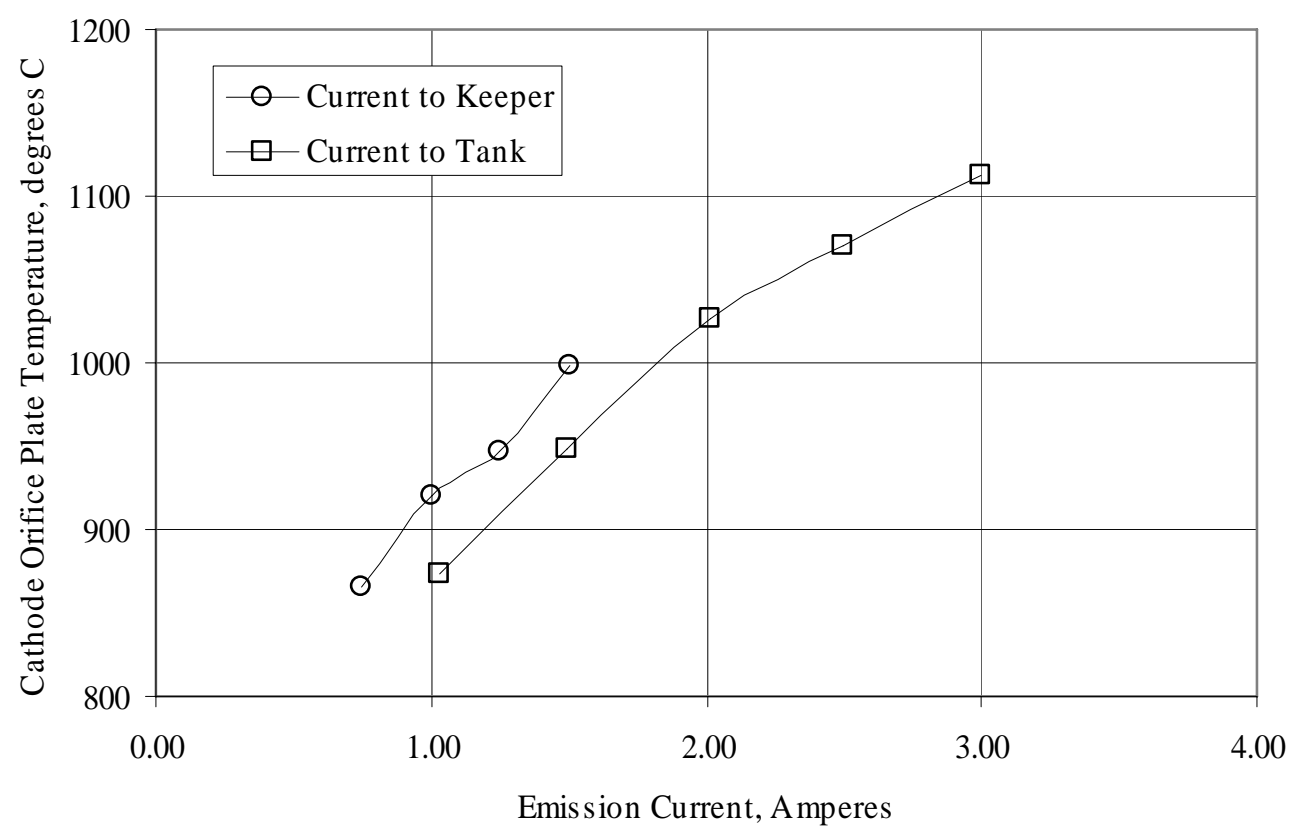

Figure 7.-Cathode assembly orifice plate temperature as a function of emission current.

over a range of 8 to $12 \mathrm{sccm}$. Figure 7 shows the hollow cathode orifice plate temperature for operation with $0.75 \mathrm{~A}$ to $1.50 \mathrm{~A}$ emission current to the keeper and, separately, 1.0 to $3.0 \mathrm{~A}$ emission current to the vacuum facility walls ('tank'). These data were obtained at an Ar flow rate of $10 \mathrm{sccm}$. Keeper voltages, when operated, were $<45 \mathrm{~V}^{\ddagger \ddagger}$, and voltages to the vacuum facility walls were less than $70 \mathrm{~V}$. As indicated the cathode orifice plate temperature ranged from about 875 to $1100{ }^{\circ} \mathrm{C}$ for 1.0 to $3.0 \mathrm{~A}$ emission; values consistent with stable, long-life operation. Using the methodology described in reference 1 estimated cathode assembly life based on emitter life is $>100 \mathrm{khr}$ for all conditions. The corresponding gas connector temperatures ranged from about 250 to $300{ }^{\circ} \mathrm{C}$.

\footnotetext{
\#¥t It was concluded from the performance characterization tests that the keeper would likely not be required in the final design used by the commercial firm.
} 


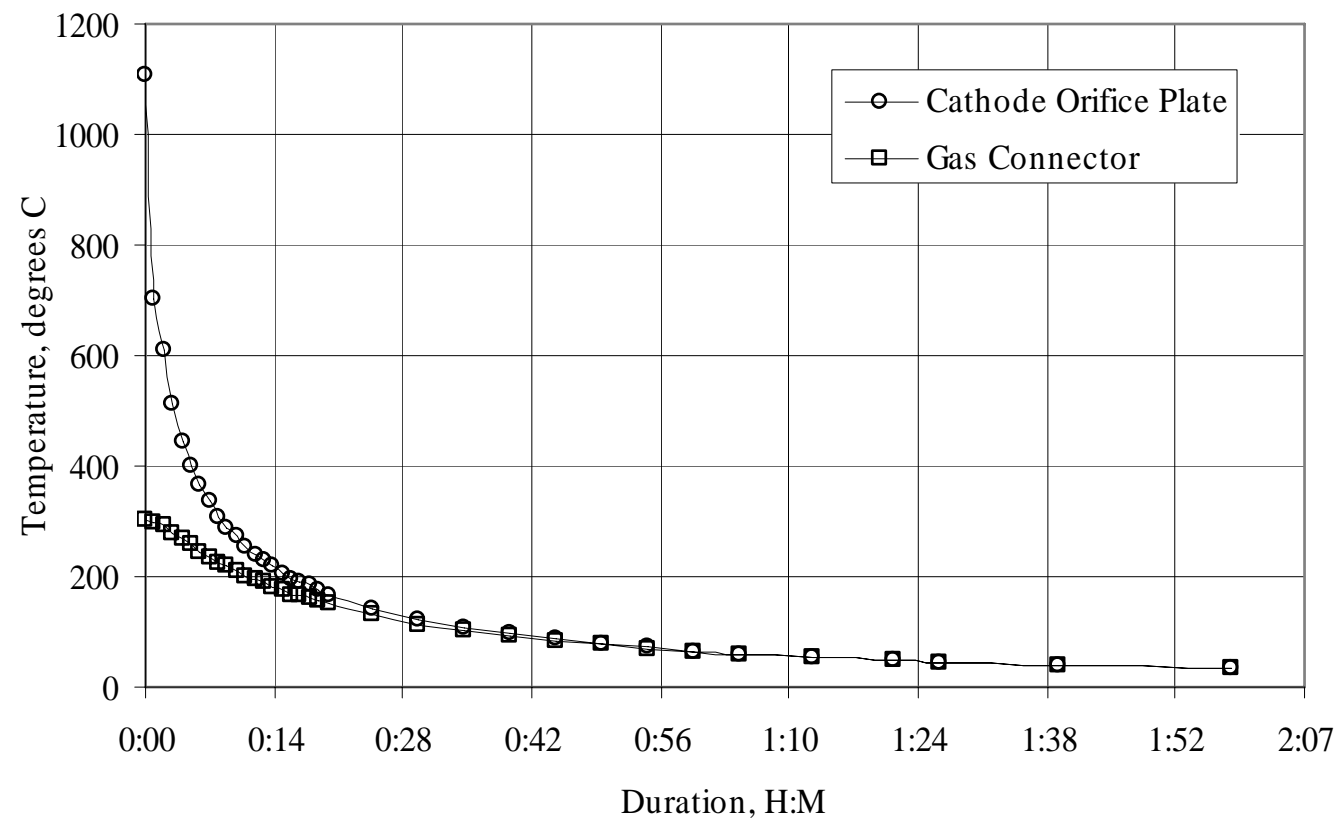

Figure 8.-Temperature as a function of duration after power removed at $t=0: 00$.

Cathode assembly temperatures were obtained after power was cut-off and the assembly was maintained under hard vacuum. These data are shown in figure 8 . As indicated it takes approximately $1 \mathrm{hr}$ for the orifice plate temperature to drop below $65^{\circ} \mathrm{C}$, and about $2 \mathrm{hr}$ to drop below $35^{\circ} \mathrm{C}$. The general criteria applied to space cathodes are to allow the temperature to drop below $35^{\circ} \mathrm{C}$ prior to exposure to atmosphere to preclude formation of oxides and potential damage to the emitter low-work-function surface. For this commercial application a number of approaches can be applied to expedite the turnaround of the cathode to atmosphere and back to vacuum. These include exposure of the cathode assembly to atmosphere after $1 \mathrm{hr}$ cool down while applying a cover gas of Ar during venting and atmospheric exposure operations, or sealing the cathode assembly within a separate vacuum enclosure while immediately venting the vacuum facility to atmosphere after PECVD processing.

Space cathodes also undergo a lengthy process of conditioning once they have been exposed to atmosphere and before they can be safely returned to operation to preclude potential damage due to reactive contaminants, particularly water vapor. These processes include elaborate feed system bake outs and other protocols, and a time/temperature conditioning sequence which is applied to the cathode emitter. These processes obviously would be prohibitive and excessive for this application. They can be dispensed with by simply applying a singular initial emitter conditioning followed by continuous Ar gas purge of appropriate magnitude whenever the cathode is subsequently exposed to atmosphere. With appropriate precautions relative to processing there is no reason to believe that the cathode would not operate for $>>1 \mathrm{khr}$.

\section{Cost}

A cost-of-manufacturing analysis has not been performed on the cathode assembly. However some statements relative to cost can be made. The flange assembly and the associated commercial power supplies required to operate the hollow cathode require an initial procurement of the order of \$5 K.

The hollow cathode, the life-limited component which is the direct substitute for the tungsten cathode filament in the PECVD process, should be able to achieve the $<\$ 2$ per hour-of-operation objective. For space cathodes much of the cost is related to manufacturing of the emitter and the heater subassembly. 
Both subassemblies require a large number of in-process inspection steps utilizing complex and expensive analysis techniques. These have been avoided in the design of the cathode assembly described herein.

The use of commercial grade emitters without the requirements for material and process specification normally imposed by NASA reduces this component cost by an order-of-magnitude to about $\$ 200$. This cost can be reduced further by fabricating emitters from rolled Ta foil doped with an emissive mix, a technique used by the author and others previously quite successfully (refs. 3 and 4). ${ }^{\S \S}$ The use of bulk heater cable to manufacture the heater subassembly and eliminating unnecessary inspection steps imposed on heaters used for space cathodes reduces the manufacturing cost by much more than an order-ofmagnitude, with material costs for the subassembly of only about $\$ 100$.

Other material cost reductions can be achieved by substituting Tantalum for the tube material. The cost of Ta is about a factor of 17 less per unit length as compared to Mo-Re; about $\$ 50$ for the tube material. Tantalum is an adequate substitute and has been used extensively by the author, although it does form non-volatile oxides which can cause embrittlement if oxidized. The remaining processes of significance relative to manufacturing include machining of the orifice plate and the keeper, and welding of the orifice plate to the tube.

Excluding the keeper subassembly the total parts count for the hollow cathode is 7, three of which (emitter, gas connector, and power connect) are unmodified COTS components and a fourth (the swaged cable) is fabricated from a COTS cable. Total labor hours for fabrication and assembly of the hollow cathode are less than $16 \mathrm{hr}$ per assembly.

\section{Conclusion}

Under a commercial agreement plan with a U.S. firm, NASA developed a simple cathode assembly for use as an electron source for the production of diamond-like coatings, as replacement for thermionic filament cathodes. The features of the cathode were designed to satisfy the needs of the specific application, and these were developed based on know design criteria established during prior space cathode developments. The cathode satisfactorily demonstrated the operational, design, and cost requirements of the commercial application.

NASA continues to pursue commercialization of cathode technology via licensing agreements with U.S. private industry for both space and terrestrial applications.

\section{References}

1. Patterson, M.J., et al., "Recent Development Activities in Hollow Cathode Technology,” IEPC Paper no. 01-270, October 2001.

2. Zakany, J.S. and Pinero, L.R., "Space Station Cathode Ignition Test Status at 32,000 Cycles,” IEPC Paper no. 97-167, August 1997. Also NASA/TM-97-206293.

3. Patterson, M.J., "Low-Power Ion Thruster Development Status,” AIAA Paper no. 98-3347, July 1998. Also NASA/TM-1999-208822.

4. Mirtich, M.J. and Kerslake, W.R., "Long Lifetime Hollow Cathodes for 30-CM Mercury Ion Thrusters,” AIAA Paper no. 1976-985, November 1976.

\footnotetext{
${ }^{\S \S \S}$ Depending upon the operating conditions for the hollow cathode, it may be possible to extract the emitter without damaging the tube. This would reduce the recurring cost to the emitter only.
} 


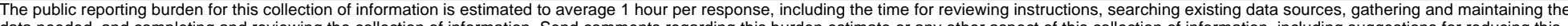

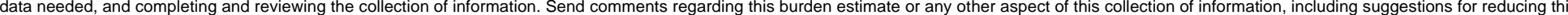

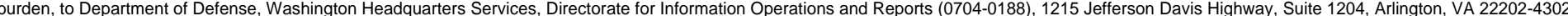

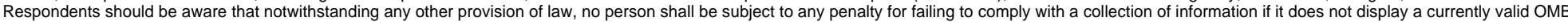
control number.

PLEASE DO NOT RETURN YOUR FORM TO THE ABOVE ADDRESS.

\section{REPORT DATE (DD-MM-YYYY) \\ 2. REPORT TYPE \\ 3. DATES COVERED (From - To)}

01-09-2007

\section{TITLE AND SUBTITLE}

Technical Memorandum

Robust Low-Cost Cathode for Commercial Applications

5b. GRANT NUMBER

5c. PROGRAM ELEMENT NUMBER

\section{AUTHOR(S)}

Patterson, Michael, J.

\section{5d. PROJECT NUMBER}

5e. TASK NUMBER

5f. WORK UNIT NUMBER

WBS 346620.04.05.03.11

8. PERFORMING ORGANIZATION

REPORT NUMBER

E-16155

National Aeronautics and Space Administration

John H. Glenn Research Center at Lewis Field

Cleveland, Ohio 44135-3191

\section{SPONSORING/MONITORING AGENCY NAME(S) AND ADDRESS(ES)}

National Aeronautics and Space Administration

Washington, DC 20546-0001

\section{DISTRIBUTIONIAVAILABILITY STATEMENT}

Unclassified-Unlimited

Subject Category: 20

Available electronically at http://gltrs.grc.nasa.gov

This publication is available from the NASA Center for AeroSpace Information, 301-621-0390

\section{SUPPLEMENTARY NOTES}

\section{ABSTRACT}

Under funding from the NASA Commercial Technology Office, a cathode assembly was designed, developed, fabricated, and tested for use in plasma sources for ground-based materials processing applications. The cathode development activity relied on the large prior NASA investment and successful development of high-current, high-efficiency, long-life hollow cathodes for use on the International Space Station Plasma Contactor System. The hollow cathode was designed and fabricated based on known engineering criteria and manufacturing processes for compatibility with the requirements of the plasma source. The transfer of NASA GRC-developed hollow cathode technology for use as an electron emitter in the commercial plasma source is anticipated to yield a significant increase in process control, while eliminating the present issues of electron emitter lifetime and contamination.

\section{SUBJECT TERMS}

Cathodes; Hollow cathodes; Electric propulsion

\section{SECURITY CLASSIFICATION OF}

a. REPORT

$\mathrm{U}$ $\mathrm{U}$

\section{LIMITATION OF} ABSTRACT

UU

18. NUMBER
OF
PAGES
17

\section{SPONSORING/MONITORS ACRONYM(S) \\ NASA; AIAA \\ 11. SPONSORING/MONITORING REPORT NUMBER \\ NASA/TM-2007-214984; AIAA-2007- 1570} PAGE U

19a. NAME OF RESPONSIBLE PERSON STI Help Desk (email:help@sti.nasa.gov) 19b. TELEPHONE NUMBER (include area code) 301-621-0390 

